\title{
Play-solicitation behavior in juvenile male and female rats
}

\author{
D. H. THOR and W. R. HOLLOWAY, JR. \\ Edward R. Johnstone Training \& Research Center, Bordentown, New Jersey
}

\begin{abstract}
Play-solicitation and social investigatory behaviors were observed in male and female juvenile rats exposed to playful and nonplayful juvenile social stimuli. A nonplayful state was induced by treatment with scopolamine HBr. In Experiment 1, the play-8olicitation behavior of males exposed to nonplayful stimuli was reliably greater than that of females; social investigation did not differ by gender. In Experiment 2, males and females were exposed to nonplayful male and female stimuli. Male subjects engaged in more soliciting than did female subjects, and male social stimuli were subjected to more soliciting than were female social stimuli. Experiment 3 compared the influence of varying social deprivation intervals on play soliciting by male juveniles. Although social investigation did not vary reliably with interval of social deprivation, play soliciting increased reliably with longer intervals of isolation. In Experiment 4, playsoliciting behavior of males exposed to nonplayful males correlated positively and reliably with play fighting behavior upon exposure to normally playful males. The results support the proposal that some specific behaviors functionally provoke interactive play fighting.
\end{abstract}

Play solicitation or play signaling has been described as a set of behaviors functionally inciting social play or signaling readiness to engage in social play (Darwin, 1873; Fagen, 1981). In the juvenile rat, specific behaviors classified as play soliciting include pounce, tail-pulling, hair-pulling, crawl over/under, and darting (Meaney \& Stewart, 1981; Poole \& Fish, 1976). When observed in pairs or in small groups, certain individuals initiate more play than others and soliciting behaviors precede bouts or sequences of rough-and-tumble play fighting, often with no subsequent, well-defined roles of attacker and defender.

In the broad context, juvenile play fighting in rats has only recently gained a significant degree of research attention. Investigations have ranged from descriptive (Poole \& Fish, 1975, 1976) and ontogenetic (Meaney \& Stewart, 1981; Panksepp, $1981)$ to analyses of pharmacological (Beatty, Dodge, Dodge, White, \& Panksepp, 1982), physiological (Beatty, Dodge, Traylor, Donegan, \& Godding, 1982; Thor \& Holloway, 1982), and hormonal (Meaney \& Stewart, 1981) variables. In the absence of any distinctive, historical background of experimental literature, recent reports have tended to be exploratory in character.

Specific play behaviors are often viewed as component acts, positively correlated, and occurring in bouts or sequences, each composed of one or more (usually several) distinctive behaviors (e.g.,

The authors' mailing address is: Research Department, Johnstone Training \& Research Center, Bordentown, New Jersey 08505 . chasing, wrestling, boxes, pinning). A sequence of specific behaviors has been observed (Poole \& Fish, 1975, 1976), and some specific behaviors, selected for their lack of ambiguity and consequent ease of scoring and quantification have been incorporated as measures of play fighting (Panksepp, 1981; Panksepp \& Beatty, 1980).

Our emphasis in this report is on several behaviors that have been classified as soliciting or inciting play. We reasoned that a nonplayful social stimulus might constitute a standard stimulus animal, eliciting play solicitation without involving other facets of social play that involve bipartisan engagement.

Scopolamine was used to induce a nonplayful, but active, state in juveniles used as social stimuli. This drug has recently been demonstrated to effectively block juvenile play without diminishing attractiveness to other juveniles (Thor \& Holloway, 1983). Other drugs (amphetamine, methylphenidate, caffeine, naloxone) can also inhibit juvenile play, but they are less effective than scopolamine, induce stereotypies in higher dosages needed to completely block social play, induce amicable social behaviors, or inhibit normal activity in high dosages. Scopolamine significantly inhibits play in a dosage of $0.3 \mathrm{mg} / \mathrm{kg}$, but can be given in a dosage as high as $10 \mathrm{mg} / \mathrm{kg}$ without diminishing social attractiveness. Amphetamine is a potent inhibitor of social play in juvenile rats (Beatty, Dodge, Dodge, et al., 1982), but has been described by Humphreys and Einon (1981) as decreasing social attractiveness in a choice test comparison with an untreated juvenile ( $2 \mathrm{mg} / \mathrm{kg}$ of d-amphetamine sulfate).

Play soliciting of a normal juvenile to a nonplay- 
ful social stimulus resembles soliticing to a playful stimulus. The principal difference is that introductory play solicitations do not merge into typical juvenile play fighting. The subject intermittently continues to solicit until the lack of social reinforcement results in extinction of the behavior (preliminary observations). Consequently, soliciting behavior is readily evident and can be viewed as a distinctive phase of social play in the juvenile rat.

The goal of this investigation is to confirm and extend gender differences (Beatty, Dodge, Traylor, et al., 1982; Meaney, Dodge, \& Beatty, 1981; Meaney \& Stewart, 1981) and social isolation effects (Panksepp \& Beatty, 1980) in play solicitation of juveniles observed in pairs or larger groups. We anticipated comparable results with individual subjects exposed to nonplayful social stimuli.

\section{EXPERIMENT 1}

Male and female juvenile rats were socially isolated. In their home cages, each juvenile was exposed to a nonplayful social stimulus. Play-solicitation frequency and duration of social investigation were observed for each male and female juvenile subject. It was anticipated that male juveniles would engage in significantly more frequent play solicitations than female juveniles (Beatty, Dodge, Traylor, et al., 1982).

\section{Method}

Subjects. Eleven males and 11 females, 35 days of age, of the Long Evans strain, served as subjects. Eleven males of the same age and strain served as social stimuli. All were weaned at 21 days and were maintained in group cages until socially isolated at 35 days of age. Isolation cages were pan-type polypropylene $(41 \times 51 \times 22 \mathrm{~cm})$ with an overhead wire grid supporting food pellets and water bottle (Lab Products Inc.). Social stimuli were maintained in group cages throughout.

Scopolamine treatment of social stimuli. Each stimulus animal was treated with $10 \mathrm{mg} / \mathrm{kg}$ of scopolamine hydrobromide (Sigma) by intraperitoneal injection 20 min prior to social exposure testing. This dosage was selected on the basis of preliminary observations to assure reliability and general effectiveness in blocking play solicitation or response to play solicitation. The scopolamine solution was freshly prepared and administered in a volume of $.1 \mathrm{ml}$ per $100 \mathrm{~g}$ of weight.

Procedure. Each subject was isolated for $48 \mathrm{~h}$ prior to test, and then each social stimulus was exposed to one male and one female juvenile subject on separate days. Order of exposure was counterbalanced. The scopolamine-treated social stimulus was placed in the home cage of the male or female juvenile isolate. For the next $12 \mathrm{~min}$, the behavior of the subject was continuously observed. Play-solicitation frequency (Meaney \& Stewart, 1981; Poole \& Fish, 1975) was recorded, as was time engaged in social investigation. Play solicitation was defined (after Beatty, Dodge, Traylor, et al., 1982; Meaney \& Stewart, 1981) as (1) pouncing on the stimulus animal and pulling on hair or tail, or (2) pouncing on the stimulus animal followed by rapid darting movements away from the stimulus animal. Social investigation was defined as following, sniffing, nosing, or grooming of the stimulus animal. Frequency of solicitations and total duration of social investigation were recorded by hand-held switches activating pens of an operations recorder.
All observations were made in dim red light during the normally dark phase of a 12:12 h, light-dark cycle.

\section{Results}

No scopolamine-treated stimulus animal engaged in play solicitation. The social-stimulus animals ambulated normally about the cage but did not engage in reciprocal social play (no wrestling, boxing, or tumbling behavior was observed). On occasion, a stimulus animal was inverted and momentarily pinned.

The data are presented in Figure 1. Mean social investigation times and play-solicitation frequencies are given for males and for females over successive 2-min intervals. Repeated-measures ANOVAS (groups $x$ intervals) were computed with each set of data.

Social investigation. Males and females did not differ in mean length of time engaged in social investigation of the standard social stimulus $[F(1,20)$ $=.17]$. Investigation time was maximal during the first 2 min and decreased significantly over successive 2 -min intervals $[F(5,100)=40.86, p<.001]$. The interaction was nonsignificant $[F(5,100)=.81]$. Evidently, isolate male and female juveniles find a novel scopolamine-treated juvenile comparably attractive.

Play solicitations. Males and females differed in mean play-solicitation frequency $[F(1,20)=4.72$, $\mathrm{p}<.05]$, with males soliciting more $(M=22.6$, $\mathrm{SE}=2.6)$ than females $(M=11.9, \mathrm{SE}=4.1)$. Maximum solicitations for both males and females occurred during the second 2-min interval. Over all six intervals, mean solicitation frequency declined significantly $[F(5,100)=4.30, p<.01]$. The interaction was nonsignificant $[F(5,100)=1.10]$.

Variance in frequency of play solicitation by females was great. Two females engaged in no play solicitation and two females each had only one play

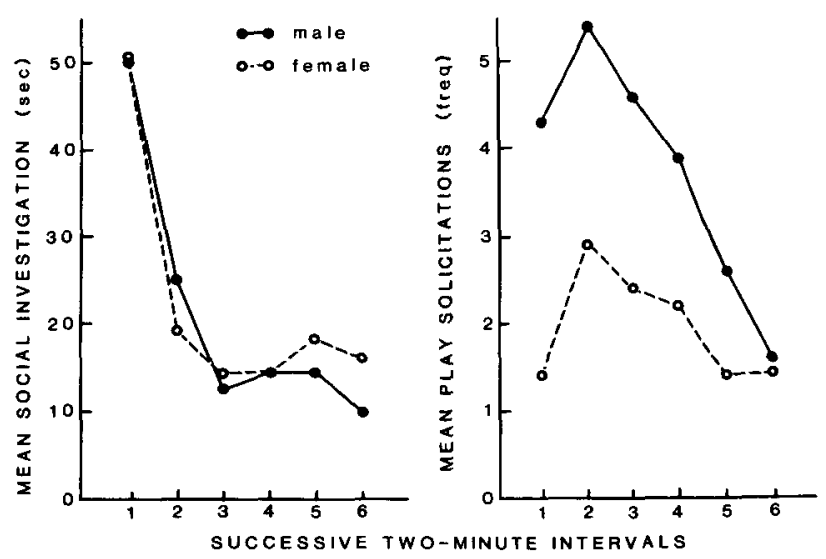

Figure 1. Mean social investigation time and play solicitations by male and female juveniles exposed to nonplayful social stimulus. 
solicitation throughout. On the other hand, three females had solicitation frequencies greater than the mean frequency for males.

\section{EXPERIMENT 2}

Categories of juvenile play-fighting measures used in recent ontogenetic investigations by Meaney and Stewart (1981) and by Panksepp and Beatty (1980) are essentially related to the earlier classification schemes of Grant and Mackintosh (1963) and Poole and Fish (1975). Brief commentary on play-initiation behavior in a number of reports suggests a consensual validity of definition. One element of social play, "pounce," was described by Poole and Fish (1975) as: "all movements in which the body of one rat is moved over the back of the partner" (p. 64). "Pounce," in addition to "charge," were conjointly described as "a form of teasing which may elicit play in a hitherto unresponsive animal" (p. 69).

On the basis of our observations in Experiment 1 and a review of the definitions of play-initiation measures that have recently been proposed, we combined the definition by Poole and Fish (1975) with that of more recent definitions (Beatty, Dodge, Traylor, et al., 1982; Meaney \& Stewart, 1981; Panksepp \& Beatty, 1980), and concentrated on the frequency of "crossover" behavior. Crossover is here defined as a traversal by the subject over or under the median plane of the stimulus. A crossover thus includes: crawlover, crawlunder, pounce, and any other gross movement that results in a traversal over or under the stimulus. We also observed the frequency of "darting" episodes. A dart is here defined as a rapid running movement by the subject toward, parallel to, or away from the stimulus. Finally, we observed the frequency of "aggressive grooming" episodes. A groom of this variety differs from normal grooming behavior in that it is more rapid, vigorous, and associated with hair pulling in the neck and shoulder areas. These three behaviors (crossover, dart, and groom) were presumed to constitute play solicitations emitted by the subject to stimulate interactive social play.

Since Experiment 1 was limited to male social stimuli, it was of interest to compare male and female juveniles when used as scopolamine-treated social stimuli. Gender-related odors or movements and/ or size differences may contribute to gender differences in play-solicitation behavior when male and/ or female subjects are exposed to male and female scopolamine-treated social stimuli (see Meaney \& Stewart, 1981).

\section{Method}

Subjeets. Twenty Long-Evans juvenile rats were used as subjects, and eight were used as social stimuli; half of each group were of each sex. All were weaned at 21 days and were tested at 35-40 days of age.

Scopolamine treatment of social stimuli. Each social stimulus was pretreated with $10 \mathrm{mg} / \mathrm{kg}$ scopolamine hydrobromide, as described in Experiment 1.

Procedure. Each subject was individually housed for 6 days prior to testing in the isolation cages described in Experiment 1. Social stimuli were maintained separately in group cages of like sex when not used as social stimuli.

Order of exposure to male and female stimuli was counterbalanced, with half of each sex exposed to one sex and then to the other. Each exposure was for 6 min during the normally dark phase of the 12:12 h light-dark cycle. Beginning $15 \mathrm{~min}$ after receiving scopolamine, four social stimuli were each repetitively exposed to five subjects of the same sex. On the second day of testing, four additional social stimuli were similarly exposed to five subjects each. Each subject was therefore exposed to two social stimuli, and each social stimulus was exposed to five subjects. A limit of five exposures was made to ensure that the social stimulus was maximally unresponsive to play solicitations of the subject without giving additional scopolamine (the blocking effect on play is normally effective for longer than $1 \mathrm{~h}$; Thor \& Holloway, 1983).

During test exposures, the frequency of play solicitations (crossovers, grooms, and darts) was observed and recorded.

\section{Results}

As in Experiment 1, social stimuli were active, but unresponsive to play solicitation by the subjects. Social stimuli did not engage in play-solicitation behavior.

Means and standard errors of each measure by gender of subject and by gender of stimulus are given in Figure 2. Three-way repeated-measures ANOVAs (gender of subject $x$ order $\times$ gender of stimulus) were computed with each of the three sets of data.

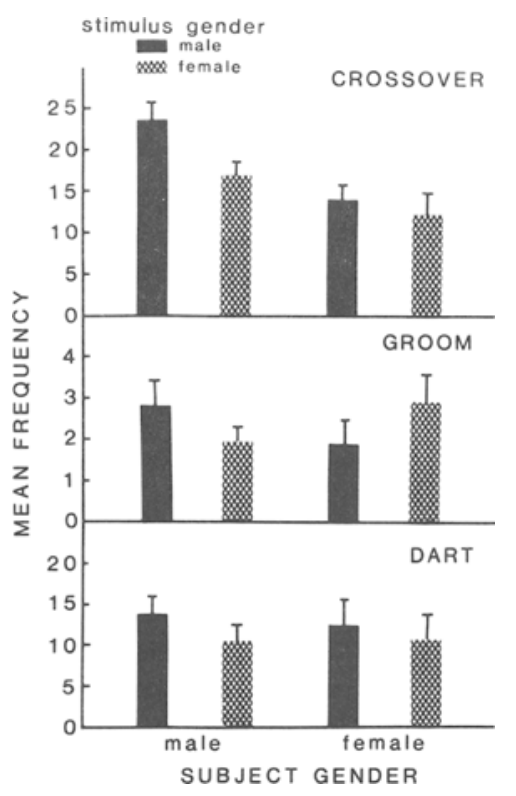

Figure 2. Mean crossover, groom, and dart frequencles of male and female juveniles exposed to monplayful male and female social stimuli. 
Crossover. Males engaged in more crossover behavior than did females $[F(1,16)=5.59, p<.05]$. Male social stimuli were also subject to more crossovers than were female social stimuli $[F(1,16)=7.39$, $\mathrm{p}<.02$ ]. Order was nonsignificant, as were all firstorder interactions; the second order interaction was significant $[F(1,16)=5.77, p<.05]$. The three-way interaction was significant because order effects were different for male and female subjects: male subjects were more responsive to male stimuli when a male was first exposed, and females were more responsive to male stimuli when a female was first exposed (the small sample size of subgroups does not warrant confidence in this observation).

Groom. Male stimuli were subject to more aggressive grooming episodes by males than were female stimuli, and female stimuli were subject to more aggressive grooming episodes by females than were male stimuli. This interaction (gender of subject $\times$ gender of stimuli) was reliable $[F(1,16)=6.42$, $\mathrm{p}<.025]$. All other interactions, as well as the main effects, were nonsignificant for the groom frequency data.

Dart. There were no reliable mean differences for main effects or for interactions with the dartfrequency data.

\section{EXPERIMENT 3}

Gender differences in the solicitation measures used in Experiments 1 and 2, particularly the crossover measure, are compatible with the established finding that male juvenile rats engage in more social play than do female juvenile rats. Play-solicitation behavior may also be viewed as a distinctive subcategory of juvenile play or as an introductory phase of play. In either case, it is reasonable that playsolicitation behavior increases as a function of prior social deprivation. Panksepp and Beatty (1980) have demonstrated a significant increase in social solicitation by weanlings isolated for 3 days. In this study, social solicitation was a general category that included several discrete social behaviors (sniffing, social grooming, over-under behavior, pouncing, charging, mounting, boxing).

In Experiments 1 and 2, the subjects were socially isolated prior to testing on the assumption that playsolicitation behavior is increased by social deprivation. Experiment 3 tested this assumption with the solicitation measures used in Experiment 2 (groom frequency was excluded on the basis of relatively low frequency of occurrence). It was hypothesized that social deprivation for intervals of 24 or $168 \mathrm{~h}$ will significantly increase play solicitation (as measured by dart and crossover frequency) in comparison with social deprivation for only $1 \mathrm{~h}$.

\section{Method}

Subjects. Thirty male juvenile rats were used as subjects. All were 36-40 days of age at time of testing. Ten male juveniles were used as social stimuli and were group housed when not exposed to subjects.

Scopolamine treatment of social stimulus. Each stimulus male was pretreated with scopolamine, as in Experiment 1.

Procedure. Each subject was socially isolated for 1, 24, or $168 \mathrm{~h}$ prior to testing with a scopolamine-treated social stimulus. A 1-h social deprivation interval was used to avoid pretest interference by displacement of cagemates immediately prior to test; this condition was considered basically equivalent to a socially nondeprived control condition. The test procedure was that described in Experiment 2, except that observation time was $6 \mathrm{~min}$. Social investigation (sniffing, following, nosing, or nonaggressive grooming), dart frequency, and crossover frequency were recorded as described in Experiments 1 and 2. Time of testing and test conditions were the same as those described in Experiments 1 and 2.

\section{Results}

As in Experiments 1 and 2, social stimuli were active but unresponsive to play solicitation by subjects. Means and standard errors of all measures are given in Figure 3. A one-way ANOVA was computed with each set of data. Tukey HSD tests were used for all paired mean comparisons.

Investigation time. Mean social investigation time decreased with longer intervals of pretest social isolation, but the mean difference was nonsignificant $[F(2,27)=2.03, p>.10]$.

Dart frequency. Mean dart frequency increased significantly with longer intervals of pretest social isolation $[F(2,27)=3.62, p<.05]$. The mean difference between 1 and $168 \mathrm{~h}$ of pretest social isolation was significant $(\mathrm{p}<.05)$; all other paired mean differences were nonsignificant. A less conservative t test (two-tail) was significant for the 1- and 24-h mean difference $[\mathrm{t}(18)=2.43, \mathrm{p}<.05]$.

Crossovers. Mean crossover frequency also increased significantly with longer intervals of social isolation $[\mathrm{F}(2,27)=10.25, \mathrm{p}<.001]$. The mean difference between 1 and $168 \mathrm{~h}$ was significant $(p<.01)$;

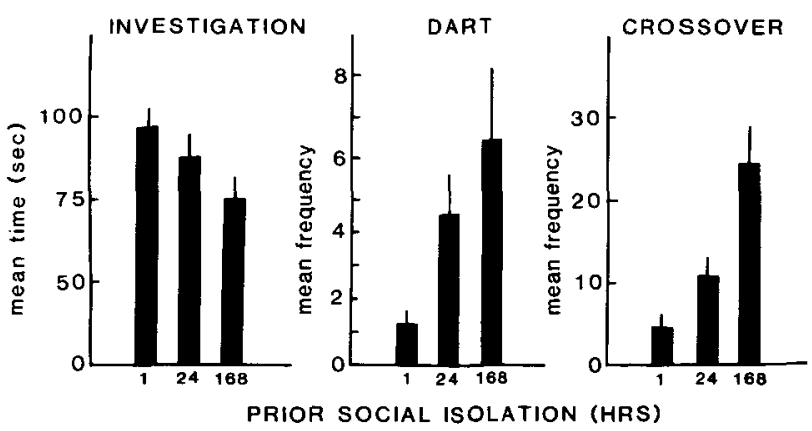

Figure 3. Mean social investigation time, dart frequency, and crossover frequency by male juveniles exposed to nonplayful male social stimuli after social deprivation intervals of 1,24 , or $168 \mathrm{~h}$. 
the mean difference between 24 and $168 \mathrm{~h}$ was significant $(\mathrm{p}<.05)$; and the mean difference between 1 and $24 \mathrm{~h}$ was nonsignificant $(\mathrm{p}>.05)$ [a less conservative $t$ test (two-tail) for the 1 - and 24 -h mean difference was significant $[t(18)=2.21, p<.05]$.

\section{EXPERIMENT 4}

The results of Experiments 2 and 3 suggest that the play-solicitation measures of crossover frequency and darting frequency, as determined by social exposure to an attractive, but nonplayful, social stimulus, may be predictive of playfulness when exposed to a normal juvenile. This hypothesis is implicit in discussions of play-solicitation behavior and has been subject to some quantification based upon measures of solicitation and play behaviors within observation intervals, that is, several juveniles simultaneously observed in group situations (Poole \& Fish, 1976).

To our knowledge, there are no reports of juvenile play-soliciting behavior determined independently of interactive social play and, in turn, correlated with normal play. Experiment 4 examined the magnitude of the empirical correlation. It was anticipated that play solicitation observed when a juvenile subject is exposed to a nonplayful, scopolaminetreated juvenile is positively and significantly correlated with measures of social play, viz, pinning frequency and play fighting time when exposed to an untreated, playful juvenile.

\section{Method}

Subjects. Twenty male juvenile rats were used as subjects, all were 35-40 days of age at time of testing. All were socially isolated for 6 days prior to test. Twenty male juveniles of the same age were used as social stimuli. All social stimuli were routinely maintained in group cages when not exposed to subjects.

Scopolamine treatment of social stimuli. Half of the stimulus males were pretreated with scopolamine as described for Experiment 1 on each of 2 successive days.

Procedure. Each subject was individually tested in its home cage by exposure to a social stimulus animal for $6 \mathrm{~min}$ on each of 2 successive days. Order of exposure to a scopolamine-treated male juvenile (nonplayful) or to a nontreated male juvenile (playful) was counterbalanced.

When exposed to a nonplayful juvenile stimulus, frequencies of darting and of crossovers by the subject were recorded, as was the duration of social investigation. When exposed to a playful juvenile stimulus, the duration of play fighting (pinning, wrestling, boxing) was recorded in addition to pin frequency
Table 1

Means and Variances of Social Play, Play Solicitation, and Social Investigation

\begin{tabular}{llrr}
\hline Social Stimulus & \multicolumn{1}{c}{ Behavior } & Mean & \multicolumn{1}{c}{ SE } \\
\hline \multirow{3}{*}{ Playful } & Pin* & 19.9 & 2.5 \\
& Play Fight ${ }^{*}$ & 147.2 & 13.7 \\
& Investigation $\dagger$ & 51.9 & 4.3 \\
\multirow{2}{*}{ Nonplayful } & Dart* & 7.1 & 1.3 \\
& Crossover* & 25.0 & 2.6 \\
& Investigation $\dagger$ & 83.8 & 5.7 \\
\hline
\end{tabular}

*Frequency. tIn seconds.

and duration of social investigation (sniffing, following, nosing, or grooming). Pin frequency was recorded without reference to identity of the juvenile pinning or being pinned.

\section{Results}

Scopolamine-treated juveniles serving as social stimuli rarely engaged in playful interactions and were never observed to pin a subject. In contrast, nontreated juveniles serving as social stimuli engaged in normal, reciprocal play with the subjects. Order of exposure to playful and nonplayful social stimuli did not reliably affect play or solicitation measures.

Means and variances (SEs) of play fighting and play-solicitation measures are given in Table 1. Social investigation bouts that normally preceded play fighting or solicitation were longer after introduction to a nonplayful $(M=83.8 \mathrm{sec})$ than to a playful $(M=51.9 \mathrm{sec})$ stimulus $[t(19)=4.34, p<.001]$. Initiation of social play appears to be a normal transition phase after a variable interval of social investigation.

Pinning and play fighting measures both correlated positively and reliably $(\mathrm{p}<.001)$ with the crossover frequency measures. Darting also correlated positively and reliably with pinning $(p<.05)$ and with play fighting time $(p<.025)$. All correlations are given in Table 2 .

\section{GENERAL DISCUSSION}

Nonplayful, scopolamine-treated juveniles were used as social stimuli to assess the play-solicitation behavior of individual juveniles without reciprocal play stimulation. Scopolamine-treated juveniles were socially attractive to nontreated juveniles, and after an initial phase of social investigation, the

Table 2

Correlations Between Measures

On Exposure to Nonplayful Stimulus

\begin{tabular}{cccc} 
On Exposure to Playful Stimulus & Darting & Crossovers & Investigation \\
\hline Pinning & $.42^{*}$ & $.69 \dagger$ & -.22 \\
Play Fighting & $.46^{* *}$ & $.69 \dagger$ & -.18 \\
Investigation & -.25 & -.19 & -.06 \\
\hline
\end{tabular}

${ }^{*} p<.05 \quad * * p<.025 \quad t_{p}<.001$ 
nontreated subject engaged in repeated play solicitations to the social stimulus. The method apparently magnifies the preliminary, soliciting or inciting, phase of normal juvenile social play.

Males engaged in greater play solicitation than did females (Experiment 1). The sex difference in solicitation was most evident during the first $6 \mathrm{~min}$ after exposure to the social stimulus. The crossover measure of play solicitation (Experiment 2) was sensitive to gender of subject as well as gender of stimulus; male scopolamine-treated social stimuli elicited greater crossover frequency than did female scopolamine-treated stimuli. The stimulus gender difference was significant for males and nonsignificant for females. Aggressive groom and dart frequency did not vary significantly by gender of subject or by gender of stimulus. Prior social isolation (Experiment 3) significantly increased darting and crossover measures of play solicitation; social investigation time decreased with increasing intervals of pretest social isolation, but the decrease was not reliable. Play fighting behaviors, measured independently of play-solicitation behaviors, correlated positively and reliably with darting and crossover measures (Experiment 4).

The combined results suggest that the present method (exposure to an attractive but nonplayful social stimulus) has a distinct application in the general investigation of juvenile play solicitation. The results indicate that play-solicitation measures are sensitive to the same variables that pertain to social play, and support the conclusions of others (Humphreys \& Einon, 1981) who have proposed that social play can be a strong reinforcement and is actively sought, particularly by a socially deprived juvenile. Play-soliciting behavior by one juvenile is normally followed by interactive play that appears to be mutually stimulating and reinforcing. In the contrived situation described in the present series, soliciting behavior is revealed in greater definition. After numerous attempts to engage the social stimulus, soliciting behavior by the subject diminishes markedly (Figure 1). Poole and Fish (1976) reported a high degree of variability in playfulness among littermates and noted that the more playful individuals engage in greater play with others who are similarly playful.
The present findings generally confirm the observation by Poole and Fish (1976, p. 258) that responsiveness to play solicitation is a variable sustaining social play; although some behavioral elements of social play are emitted in response to the presence of another juvenile, other behavioral elements are response dependent.

\section{REFERENCES}

Beatty, W. W., Dodge, A. M., Dodge, L. J., White, K., \& PAnkse PP, J. Psychomotor stimulants, social deprivation and play in juvenile rats. Pharmacology Biochemistry \& Behavior, 1982, 16, 417-422.

Beatty, W. W., Dodge, A. M., Traylor, K. L., Donegan, J. C., \& Godding, P. R. Septal lesions increase play fighting in juvenile rats. Physiology \& Behavior, 1982, 28, 649-652.

DARWIN, C. The expression of the emotions in man and animals. London: John Murray, 1873.

Fagen, R. Animal play behavior. New York: Oxford University Press, 1981.

Grant, E. C., \& Mackintosh, J. H. A comparison of some of the social postures of some common laboratory rodents. $\mathrm{Be}$ haviour, 1963, 21, 246-259.

Humphreys, A. P., \& Einon, D. F. Play as a reinforcer for maze-learning in juvenile rats. Animal Behaviour, 1981, 29, 259-270.

Menney, M. J., \& Stewart, J. A descriptive study of social development in the rat (Rattus norvegicus). Animal Behaviour, $1981,29,34-45$.

Menney, M. J., Dodge, A. M., \& Bentty, W. W. Sexdependent effects of amygdaloid lesions on the social play of prepubertal rats. Physiology \& Behavior, 1981, 26, 467-472.

Panksepr, J. The ontogeny of play in rats. Developmental Psychobiology, 1981, 14, 327-332.

Panksepp, J., \& BeatTy, W. W. Social deprivation and play in rats. Behavioral and Neural Biology, 1980, 30, 197-206.

Poole, T. B., \& Fish, J. An investigation of playful behaviour in Rattus norvegicus and Mus musculus (Mammalia). Journal of the Zoological Society, London, 1975, 175, 61-71.

Poous, T. B., \& Fish, J. An investigation of individual, age and sexual differences in the play of Rattus norvegicus (Mammalia: Rodentia). Journal of the Zoological Society, London, 1976, 179, 249-260.

Thon, D. H., \& Holloway, W. R., Jr. Anosmia and play fighting behavior in prepubescent male and female rats. Physiology \& Behavior, 1982, 29, 281-285.

Thor, D. H., \& Holloway, W. R., JR. Scopolamine blocks play-fighting in juvenile rats. Physiology \& Behavior, 1983, 30, 545-549.

(Manuscript received January 20, 1983; revision accepted for publication April 25, 1983.) 